\title{
Safety, tolerability, pharmacokinetics and pharmacodynamics of AZD8055 in advanced solid tumours and lymphoma
}

\author{
A Naing*,I, C Aghajanian², E Raymond ${ }^{3}$, D Olmos ${ }^{4}$, G Schwartz $^{2}$, E Oelmann ${ }^{5}$, L Grinsted ${ }^{5}$, W Burke ${ }^{5}$, \\ R Taylor ${ }^{5}$, S Kaye ${ }^{4}$, R Kurzrock' and U Banerji*,4
}

'The University of Texas MD Anderson Cancer Center, 1515 Holcombe Boulevard, Houston, TX 77030, USA; ${ }^{2}$ Memorial Sloan-Kettering Cancer Center, 300 East 66th Street, New York, NY 10065, USA; ${ }^{3}$ Hôpital BEAUJON, 100 Boulevard du Général Leclerc, Clichy Cedex 92118 , France; ${ }^{4}$ The Institute of Cancer Research, Drug Development Unit, The Royal Marsden Hospital, Sycamore House, Downs Road, Sutton, Surrey SM2 5PT, UK; ${ }^{5}$ AstraZeneca, Alderley Park, Macclesfield SKIO 4TG, UK

BACKGROUND: This study assessed the safety, tolerability, pharmacokinetics and pharmacodynamics of the first-in-class dual mammalian target of rapamycin complex (mTORC) I/mTORC2 inhibitor, AZD8055.

METHODS: Patients with advanced solid malignancies or lymphomas were recruited into this phase I, open-label, dose-escalation study of AZD8055 starting at $10 \mathrm{mg}$ twice-daily oral dosing (BID).

RESULTS: Forty-nine patients received AZD8055. Dose-limiting toxicities were reported at $40 \mathrm{mg}(n=1), 90 \mathrm{mg}(n=1)$ and I20 mg $(n=3)$ BID; all were grade 3 rises in transaminases, reversible in all patients, apart from one who had liver metastases. The maximum tolerated dose was defined as $90 \mathrm{mg}$ BID. The most frequent adverse events assessed to be related to AZD8055 were increased alanine aminotransferase (22\%), increased aspartate aminotransferase (22\%) and fatigue (16\%). AZD8055 was rapidly absorbed (median $t_{\text {max }}$ $\sim 0.5 \mathrm{~h}$ ) and exposure increased with increasing doses. Seven patients had stable disease for $\geqslant 4$ months. Partial metabolic responses, assessed by fluorodeoxyglucose positron emission tomography, were observed at $\geqslant 40 \mathrm{mg} \operatorname{BID}(n=8$ at day 35$)$.

CONCLUSION: The maximum tolerated dose for AZD8055 is $90 \mathrm{mg}$ BID. Apart from elevated transaminases, which occurred at most dose levels, the drug had an acceptable toxicity profile; however, no RECIST responses were seen.

British Journal of Cancer (2012) 107, 1093-1099. doi:10.1038/bjc.2012.368 www.bjcancer.com

Published online 30 August 2012

(C) 2012 Cancer Research UK

Keywords: AZD8055; mTOR inhibitors; phase I

The mammalian target of rapamycin (mTOR) forms two multiprotein kinase complexes, mTORC1 and mTORC2, which regulate cell growth, survival and autophagy (Guertin and Sabatini, 2007). Dysfunction of the phosphoinositide 3-kinase (PI3K)/AKT/mTOR signalling pathway has been implicated in a wide range of cancers (Vivanco and Sawyers, 2002; Faivre et al, 2006; Liu et al, 2009). Increased mTORC1 and mTORC2 activity is associated with high levels of downstream pS6K and p4E-BP1, and pAKT levels, respectively (Guertin and Sabatini, 2007; Carew et al, 2011). Thus, the mTOR kinase presents an attractive therapeutic target for anticancer drugs. Rapamycin is a selective allosteric inhibitor of mTORC1. The mTORC1 is largely considered to be rapamycin sensitive, but recent evidence suggests that the 4E-BP1 substrate is partially resistant to rapamycin (Feldman et al, 2009; Thoreen et al, 2009). This could account for the limited success of this agent as a clinical anticancer therapy. In contrast, mTORC2 is thought to be rapamycin insensitive (Feldman et al, 2009), except after prolonged exposure, which reduces mTORC2 activity in some cell types (Sarbassov et al, 2006).

Studies of everolimus have demonstrated that suppression of tumour growth is associated with inactivation of S6K1 and reduced

\footnotetext{
*Correspondence: Dr A Naing; E-mail: anaing@mdanderson.org or Dr U Banerji; E-mail: udai.banerji@icr.ac.uk

Received 24 July 2012; revised 27 April 2012; accepted 26 July 2012; published online 30 August 2012
}

4E-BP1 phosphorylation at the threonine ${ }^{70}$ site (Boulay et al, 2004; O'Donnell et al, 2008). Preclinical data have also suggested that the clinical efficacy of rapamycin and its derivatives may be limited by the loss of the feedback inhibition loop, resulting in the activation of AKT via mTORC2 (Boulay et al, 2004; O'Reilly et al, 2006; Cloughesy et al, 2008). Consistent with this, increased AKT phosphorylation has been frequently observed in tumour tissue samples from patients treated with rapamycin (Gupta et al, 2009). There are two rapalogues (everolimus and temsirolimus) currently licensed for treatment of pancreatic neuroendocrine tumours and mantle cell lymphomas, respectively (Europeans Medicines Agency, 2011, 2012). Both rapalogues are also licensed for treatment of renal cell carcinoma (Europeans Medicines Agency, 2011, 2012). However, primary and acquired resistance to rapalogues are frequently observed in patients with advanced cancer, motivating the search for novel non-allosteric compounds, which target the mTOR kinase and subsequent mTORC1 and mTORC2 functions (Albert et al, 2010).

AZD8055 is a first-in-class dual mTORC1/mTORC2 inhibitor, which was shown to prevent the mTORC2-mediated AKT activation seen with rapalogues in preclinical models (Chresta et al, 2010). A preclinical study in vitro demonstrated that AZD8055 potently inhibits AKT on the mTORC2 site, serine ${ }^{473}$ and $4 \mathrm{E}-\mathrm{BP} 1$ phosphorylation on the rapamycin-resistant threonine ${ }^{37 / 46}$ sites (Chresta et al, 2010). In the same study, in vivo data suggested that a broad spectrum of tumours may be responsive to treatment with AZD8055 and associated with reduced levels of pAKT and pS6 
(Chresta et al, 2010). The aim of this phase I study was to assess the safety, tolerability, preliminary efficacy, pharmacokinetic (PK) and pharmacodynamic (PD) profile of AZD8055 in patients with advanced solid malignancies or lymphomas.

\section{Objectives}

The primary objective of the study was to assess the safety and tolerability of AZD8055 in patients with advanced solid tumours or lymphomas. The secondary objectives of the study were to determine the PK profile of AZD8055 following both single and multiple dosing, and to evaluate the role of renal excretion in the disposition of AZD8055; to evaluate phosphorylation levels of AKT on serine ${ }^{473}$ and of $4 \mathrm{E}-\mathrm{BP} 1$ on threonine $\mathrm{e}^{37 / 46}$ in peripheral blood mononuclear cells (PBMCs) following treatment with AZD8055; to evaluate efficacy based on best overall response of AZD8055 defined by the Response Evaluation Criteria In Solid Tumors (RECIST v1.0); and to determine inhibition of tumour glucose uptake by assessment with fluorodeoxyglucose positron emission tomography (FDG-PET).

\section{MATERIALS AND METHODS}

\section{Patients and trial design}

Patients $\geqslant 18$ years with a histological or cytological confirmed diagnosis of a refractory advanced solid malignancy or lymphoma were eligible for inclusion. Patients were required to have a World Health Organization performance status of $0-2$ with 21 days of wash out from prior treatment with chemotherapy, biological therapy, radiation therapy or other investigational anticancer therapy (not including palliative radiotherapy at focal sites). Patients were required to have adequate bone marrow, renal and hepatic function. Additional inclusion/exclusion criteria are provided in the Supplementary Section. Written informed consent was obtained from all patients before entering the study. The study was performed in accordance with the Declaration of Helsinki.

This was a multicentre, open-label, dose-escalation, safety and tolerability study of AZD8055 in patients with advanced solid tumours or lymphomas (NCT00731263). The study was conducted in four centres: Surrey, UK; Clichy, France; NY, USA and TX, USA. Eligible patients received a single dose of AZD8055 on day 1 followed 1 week later by continuous twice-daily (BID) dosing. Dosing was continued until disease progression or unmanageable drug-related toxicity. The starting dose of AZD8055 was $10 \mathrm{mg}$ with each subsequent cohort receiving an increased dose of AZD8055, determined by the Safety Review Committee (SRC), until a non-tolerated dose was reached. Following cohort 3, the study incorporated a switch from solution to the tablet formation for subsequent cohorts. Patients were required to fast for at least $1 \mathrm{~h}$ pre-dose and $1 \mathrm{~h}$ post dose.

\section{Safety}

Assessments conducted at screening, and throughout the study, included physical examination, electrocardiogram, echocardiogram, vital signs, biochemistry, haematology and urinalysis. All adverse events (AEs) were recorded from the time of informed consent until 30 days after study treatment was discontinued, using the National Cancer Institute Common Terminology Criteria (CTC) v3.0 for AEs.

Dose-limiting toxicity (DLT) was defined as any AE of CTC grade $\geqslant 3$ or laboratory abnormality (clinical chemistry, coagulation, haematology or urinalysis) together with clinical signs and symptoms within 42 days of first dose. During the study, the SRC decided to extend the DLT period from 35 to 42 days of first dose, to appropriately assess transaminase effects. The maximum tolerated dose (MTD) was defined as the last dose tested below the non-tolerated dose. A dose was considered to be non-tolerated if $\geqslant 2 / 6$ evaluable patients experienced a DLT, or if $\geqslant 2 / 3$ evaluable patients experienced a DLT in the two lowest dose cohorts if they contained three patients.

\section{PK analysis}

Non-compartmental PK analysis was conducted by the Clinical Pharmacology and DMPK, AstraZeneca using WinNonLin v4.1 (Pharsight Corporation, Mountain View, CA, USA). The lower-limit quantification of AZD8055 was $0.05 \mathrm{ng} \mathrm{ml}^{-1}$. The plasma PK parameters for a single dose included the maximum observed plasma concentration $\left(C_{\max }\right)$, time to reach $C_{\max }\left(t_{\max }\right)$, terminal elimination half-life $\left(t_{1 / 2}\right)$, area under the plasma concentration-time curve from zero to infinity (AUC), area under the plasma concentration-time curve from zero to time of the last quantifiable concentration $\left(\mathrm{AUC}_{0-\mathrm{t}}\right)$, area under the plasma concentration-time curve from zero to $12 \mathrm{~h}$ post dose $\left(\mathrm{AUC}_{0-12}\right)$, total apparent drug clearance $(\mathrm{CL} / \mathrm{F})$ and apparent steady-state volume of distribution $\left(V_{\text {ss }} / \mathrm{F}\right)$. The steady-state plasma $\mathrm{PK}$ parameters following BID multiple dosing for 28 days included $C_{\max s s}, t_{\max s s}$, observed trough concentrations of drug during the dosing interval $\left(C_{\operatorname{min~ss}}\right), t_{1 / 2}$ ss, $\mathrm{AUC}_{\mathrm{ss}}, \mathrm{CL}_{\mathrm{ss}} / \mathrm{F}$, accumulation ratio $\left(R_{\mathrm{ac}}\right)$ and temporal change from single dose to steady state ( $T_{c}$; often referred to as linearity factor). Urine PK parameters following a single dose included the renal clearance of drug from plasma $\left(\mathrm{CL}_{\mathrm{R}}\right)$ and fraction dose excreted unchanged in the urine expressed as a percentage $\left(f_{\mathrm{e}} \%\right)$.

Serial blood samples were taken pre-dose and then at specified time-points throughout days 1, 11, 15, 22 and 35 for PK analysis. Serial urine samples were collected at pre-dose and throughout the 24-h period after first dosing with AZD8055.

\section{PD analysis and tumour assessments}

Additional blood samples were taken for PBMC assessments predose, 2,8 and $24 \mathrm{~h}$ post dose on day 1 . The phosphorylation levels of AKT and 4E-BP1 were assessed by using specific antibodies to the activated target in mesoscale detection and FACS assays, respectively.

A baseline RECIST assessment by computed tomography or magnetic resonance imaging scan of the chest, abdomen and pelvis was performed before study treatment, and subsequent assessments were performed every 8 weeks.

Fluorodeoxyglucose positron emission tomography was performed at screening on patients with solid tumours with measurable lesions per RECIST and all patients with lymphoma. If significant evaluable tumour FDG uptake was present at screening, an additional scan was performed 3-4h post dose on day 11 and at the end of cycle 1 (3-4h post dose). The metabolic response was assessed by observing the percentage change in the standard uptake value $\left(S U V_{\max }\right)$ from baseline at each post-dose assessment. A metabolic response was defined as a decrease in $\mathrm{SUV}_{\max }>25 \%$, as per EORTC recommendations (Young et al, 1999). A local protocol amendment was implemented at one site to allow optional collection of pre- and post-dose paired tumour biopsies at screening and at day 15 of BID dosing. Immunohistochemistry analysis of the paired tumour biopsy samples included (but was not limited to) pAKT and pS6.

\section{RESULTS}

A total of 64 patients were enrolled into the study, of whom 49 were included in the safety, PK and efficacy analyses having received at least one dose of study treatment. The reasons for screening failure include: incorrect enrolment $(n=11)$, screen 
failed in error $(n=1)$, consent withdrawn $(n=2)$ and $\mathrm{AE}(n=1)$. Patient demographics are shown in Table 1.

Patients who received $75 \%$ of the specified dose during the 28-day period of cycle 1 and had sufficient safety evaluations, or patients who experienced a DLT, were considered evaluable $(n=42 / 49)$. Seven cohorts were completed as follows: oral solution; 10, 20 and $40 \mathrm{mg}$ BID, tablet; 40, 60, 90 and $120 \mathrm{mg}$ BID.

\section{Safety}

The median duration of exposure to AZD8055 across all cohorts was 62 days. The most frequent AEs assessed by the investigator

Table I Summary of patient demographics

\begin{tabular}{|c|c|}
\hline Demographic & Total $(n=49)$ \\
\hline Age, median (range) & $57(26-76)$ \\
\hline \multicolumn{2}{|l|}{ Sex, n (\%) } \\
\hline Male & $20(4 I)$ \\
\hline Female & $29(59)$ \\
\hline \multicolumn{2}{|c|}{ WHO performance status, n (\%) } \\
\hline 0 & $25(5 \mathrm{l})$ \\
\hline । & $23(47)$ \\
\hline 2 & I (2) \\
\hline \multicolumn{2}{|c|}{ Primary tumour location, n (\%) } \\
\hline Colorectal & $16(33)$ \\
\hline Uterus & $6(12)$ \\
\hline Head and neck & $5(10)$ \\
\hline Skin/soft tissue & $4(8)$ \\
\hline Ovary & $3(6)$ \\
\hline Renal & $3(6)$ \\
\hline Other & $12(25)$ \\
\hline \multicolumn{2}{|l|}{ Locally advanced, n (\%) } \\
\hline Yes & $15(3 \mid)$ \\
\hline No & $34(69)$ \\
\hline \multicolumn{2}{|l|}{ Prior treatment, $\mathrm{n}$ (\%) } \\
\hline Radiotherapy & $27(55)$ \\
\hline Chemotherapy & $44(90)$ \\
\hline \multicolumn{2}{|l|}{ Prior regimens } \\
\hline $1-2$ & $21(43)$ \\
\hline $3-6$ & $17(35)$ \\
\hline$>6$ & $9(18)$ \\
\hline
\end{tabular}

Abbreviation: $\mathrm{WHO}=$ World Health Organization . to be related to AZD8055 were as follows: increased alanine aminotransferase (ALT; 22\%), increased aspartate aminotransferase (AST; 22\%) and fatigue (16\%; Table 2). A summary of AEs occurring in $\geqslant 15 \%$ of all patients is provided in the Supplementary Section.

\section{Tolerability, DLTs and MTD}

During the study, three patients (6\%) required dose reductions as a result of increased transaminases, assessed to be AZD8055-related: one dose reduction each in the 60,90 and $120 \mathrm{mg}$ BID tablet groups. Within cycles 1 and 2, 11 patients $(22 \%)$ had a dose interruption, 7 of which were because of an AE. The AEs which led to a dose interruption and were assessed to be AZD8055-related in cycles 1 and 2 were as follows: increased lipase $(n=1)$, increased ALT $(n=1)$ and increased blood creatine phosphokinase $(n=1)$. In the $120 \mathrm{mg}$ BID cohort, four DLTs of grade 3 rise in transaminases (in the absence of elevated bilirubin levels) were reported in $3 / 9$ patients evaluable for DLT. BID of $120 \mathrm{mg}$, therefore, met the definition of a non-tolerated dose. The same DLT was also reported with the $40 \mathrm{mg}$ BID solution $(n=1 / 6)$ and $90 \mathrm{mg}$ BID tablet $(n=1 / 9$; Table 3$)$. The MTD was therefore defined as $90 \mathrm{mg}$ BID.

All DLTs resolved within 71 days, apart from one occurrence in the $120 \mathrm{mg}$ BID cohort that was reported as ongoing in a patient who had liver metastases at the time of the data cutoff. In the 13 patients with increased serum transaminases, of either a 2 grade shift from baseline and/or an on-treatment value of CTC grade 3, onset occurred between days 1 and 56 of dosing. For 7 of these patients, the onset was between days 22 and 35. In all instances of increased transaminases, the rises were reversible and resolved back to baseline or normal values in the majority of cases on dose reduction or interruption.

Table 3 Summary of DLTs

\begin{tabular}{lcc}
\hline DLTs & CTCAE grade & Total $^{\mathbf{a}}$ (\%) \\
\hline Increased ALT & 3 & $3(6)$ \\
Increased AST $^{\text {Increased transaminases }}{ }^{b}$ & 3 & $3(6)$ \\
\hline
\end{tabular}

Abbreviations: $A L T=$ alanine aminotransferase; $A S T=$ aspartate aminotransferase; CTCAE $=$ Common Terminology Criteria for Adverse Events; DLTs, dose-limiting toxicities. ${ }^{a}$ A patient may have experienced more than one DLT. ${ }^{b}$ Aminotransferases not specified.

Table 2 Summary of AEs considered to be AZD8055-related by the investigator occurring in $\geqslant 10 \%$ of all patients, by preferred term

\begin{tabular}{|c|c|c|c|c|c|c|c|c|c|c|c|c|c|c|c|c|c|}
\hline \multirow[b]{2}{*}{ CTCAE grade } & \multicolumn{3}{|c|}{$\begin{array}{c}\text { Total } \\
(n=49 ; \%)\end{array}$} & \multicolumn{2}{|c|}{$\begin{array}{l}10 \text { mg BID } \\
\text { solution } \\
(n=5 ; \%)\end{array}$} & \multicolumn{2}{|c|}{$\begin{array}{l}20 \text { mg BID } \\
\text { solution } \\
(n=3 ; \%)\end{array}$} & \multicolumn{2}{|c|}{$\begin{array}{l}40 \text { mg BID } \\
\text { solution } \\
(n=6 ; \%)\end{array}$} & \multicolumn{2}{|c|}{$\begin{array}{c}40 \text { mg BID } \\
\text { tablet } \\
(n=7 ; \%)\end{array}$} & \multicolumn{2}{|c|}{$\begin{array}{c}60 \mathrm{mg} \text { BID } \\
\text { tablet } \\
(n=7 ; \%)\end{array}$} & \multicolumn{2}{|c|}{$\begin{array}{c}90 \mathrm{mg} \text { BID } \\
\text { tablet } \\
(n=1 \mathrm{II} \%)\end{array}$} & \multicolumn{2}{|c|}{$\begin{array}{c}120 \mathrm{mg} \text { BID } \\
\text { tablet } \\
(n=10 ; \%)\end{array}$} \\
\hline & $1-2$ & $\geqslant 3$ & $\begin{array}{l}\text { Any grade } \\
\text { occurring in } \\
\text { cycle } 1 / 2\end{array}$ & $\mathrm{I}-2$ & $\geqslant 3$ & $1-2$ & $\geqslant 3$ & $1-2$ & $\geqslant 3$ & $1-2$ & $\geqslant 3$ & $1-2$ & $\geqslant 3$ & $I-2$ & $\geqslant 3$ & $\mathrm{I}-2$ & $\geqslant 3$ \\
\hline Nausea & $7(14)$ & 0 & $7(14)$ & $2(40)$ & 0 & I (33) & 0 & 0 & 0 & I (I4) & 0 & 0 & 0 & $2(18)$ & 0 & $1(10)$ & 0 \\
\hline ncreased GGT & $3(6)$ & $2(4)$ & $5(10)$ & 0 & 0 & 0 & 0 & I (17) & 0 & 0 & 0 & I (14) & I (14) & 0 & I (9) & $1(10)$ & 0 \\
\hline Fatigue & $8(16)$ & 0 & $8(16)$ & I (20) & 0 & 0 & 0 & $2(33)$ & 0 & I (14) & 0 & $1(14)$ & 0 & I (9) & 0 & $2(20)$ & 0 \\
\hline Hyperglycaemia & $6(12)$ & 0 & $6(12)$ & 0 & 0 & 0 & 0 & 0 & 0 & I (14) & 0 & 0 & 0 & $3(27)$ & 0 & $2(20)$ & 0 \\
\hline
\end{tabular}

Abbreviations: AEs=adverse events; $A L T=$ alanine aminotransferase; $A S T=$ aspartate aminotransferase; $B I D=$ twice-daily; CTCAE $=$ Common Terminology Criteria for Adverse Events; GGT = gamma-glutamyltransferase. 


\section{PK analysis}

AZD8055 was orally bioavailable, rapidly absorbed (median $t_{\max }$ of $\sim 0.5 \mathrm{~h}$ ) and rapidly eliminated (mean $t_{1 / 2}$ of $1.7-3.1 \mathrm{~h}$ ) following single and multiple doses across all cohorts (Table 4). Single-dose PK parameters at the MTD were $C_{\max }, 70.1 \mathrm{ng} \mathrm{ml}^{-1}$ (CV 94.2\%); $t_{\max }, 0.5 \mathrm{~h}$; and $t_{1 / 2}, 2.36 \mathrm{~h}$. Geomean plasma concentration-time plots for all cohorts are presented in Figure 1.

Following single dosing, AZD8055 demonstrated proportional increases in exposure with increasing dose across all cohorts. Following BID dosing, a proportional increase in exposure was seen with the solution formulation $(10-40 \mathrm{mg}$ ) and a greater than

Table 4 Summary of pharmacokinetic parameter data

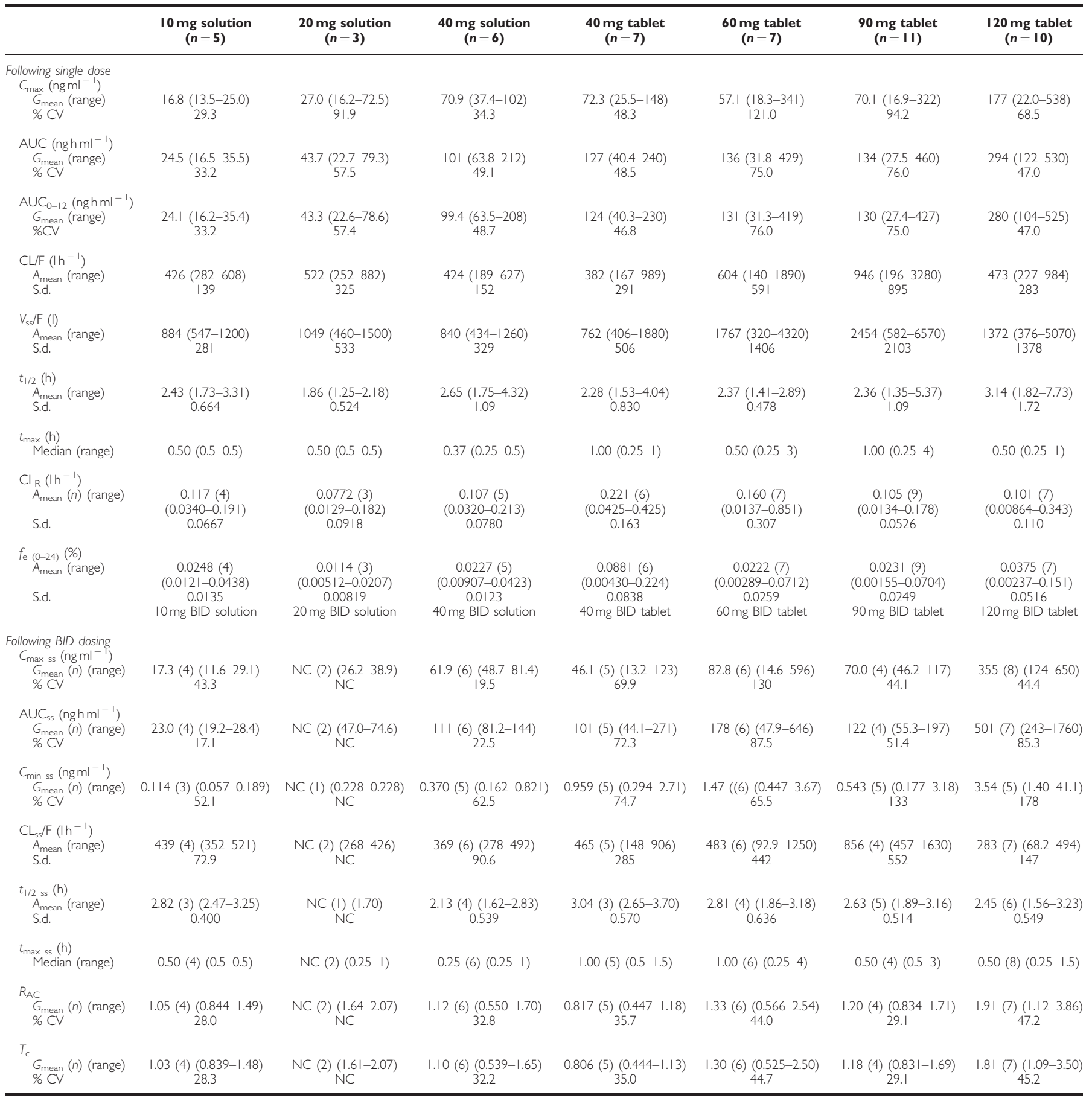

Abbreviations: $A_{\text {mean }}=$ arithmetic mean; $A \cup C=$ area under the plasma concentration-time curve from zero to infinity; $A \cup C_{s s}=$ area under the plasma concentration-time curve over a dosing interval at steady state; $A \cup C_{0-12}=$ area under the plasma concentration-time curve from zero to $12 \mathrm{~h}$ post dose; $\mathrm{BID}=$ twice-daily; $C_{\max }=$ maximum plasma concentration; $C_{\max \text { ss }}=$ maximum steady-state plasma concentration during dosing; $C_{\min \text { ss }}=$ minimum steady-state plasma concentration during dosing; $C L / F=$ total apparent drug clearance; $\mathrm{CL}_{R}=$ renal clearance from plasma; $\mathrm{CL}_{\mathrm{ss}} / \mathrm{F}=$ total apparent drug clearance at steady state; $\mathrm{fe}_{\mathrm{e}}(0-24)=$ dose fraction excreted unchanged in the urine from zero to $24 \mathrm{~h}$ post dose; $G_{\text {mean }}=$ geometric mean; $N C=$ not calculated; $R_{\mathrm{AC}}=$ accumulation ratio; $T_{\mathrm{c}}=$ temporal change (linearity factor); $t_{\max }=$ time to maximum plasma concentration; $t_{\text {max ss }}=$ time to maximum plasma concentration at steady state; $t_{1 / 2}=$ half-life; $t_{1 / 2}$ ss $=$ half-life at steady state; $V_{s s} / F=$ steady-state volume of distribution; $\% C V=$ percentage confidence value. 

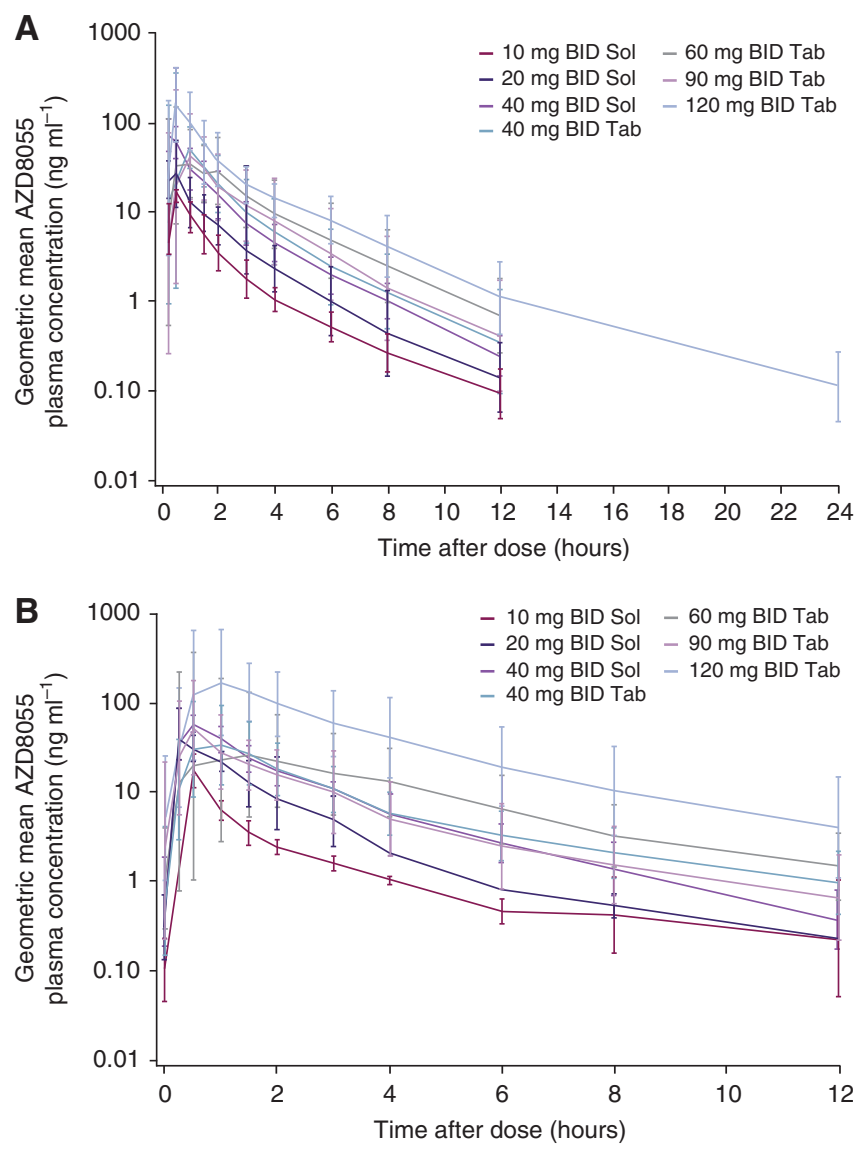

Figure I Plasma concentration time plots (geometric mean \pm s.d.). (A) Following single dose, study day I. (B) Following BID multiple dosing, study day 35. Abbreviations: $\mathrm{BID}=$ twice-daily; Sol = solution; $\mathrm{Tab}=$ tablet

proportional increase with increasing dose was seen with the tablet formulation (40-120 mg). Pharmacokinetic parameters after administration of a $40-\mathrm{mg}$ dose of either a solution or a tablet formulation were similar except for a short delay to $t_{\max }$ with the tablet. AZD8055 was observed to have low renal clearance, with $<0.25 \%$ of the dose being excreted unchanged in the urine at all dose levels in the first $24 \mathrm{~h}$ following the single dose.

\section{PD analysis}

Analysis of PBMC data at $2 \mathrm{~h}$ post dose in the MTD cohort showed a transient decrease in p4E-BP1 in $2 / 5$ patients. However, pre-dose marker levels varied substantially.

All patients in the MTD cohort with a baseline value of $>5 \%$ (6/10 patients) showed a decrease in pAKT at $2 \mathrm{~h}$ (Figure 2). However, baseline variability was noted with very low pre-dose levels $(<15 \%)$ seen in the majority of patients.

Two patients had a baseline and a post-dose tumour sample collected, the analysis of which did not show conclusive evidence of biomarker modulation for pAKT, p4E-BP1 and pS6.

\section{Efficacy}

No complete or partial responses were observed, but seven patients (10 $\mathrm{mg} n=1 / 5,40 \mathrm{mg}$ solution $n=2 / 6,60 \mathrm{mg} n=1 / 7,90 \mathrm{mg}$ $n=1 / 11$ and $120 \mathrm{mg} n=2 / 10 \mathrm{BID}$ ) had stable disease for $\geqslant 4$ months (range, 115-398 days). The primary tumour locations in these seven patients were as follows: head/neck $(n=3)$, renal $(n=1)$, thymus $(n=1)$, thyroid $(n=1)$ and melanoma $(n=1)$. At day 35, partial metabolic responses assessed by FDG-PET (a decrease in $\mathrm{SUV}_{\max }>25 \%$ ) were observed at $40 \mathrm{mg}$ BID and

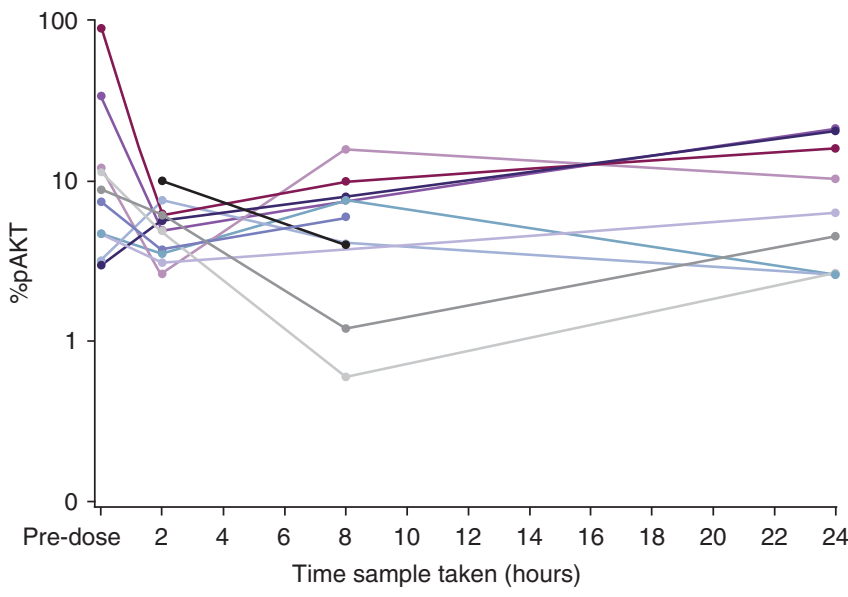

Figure 2 AKT phosphorylation levels for individual patients following dosing with AZD8055 (90 mg cohort).

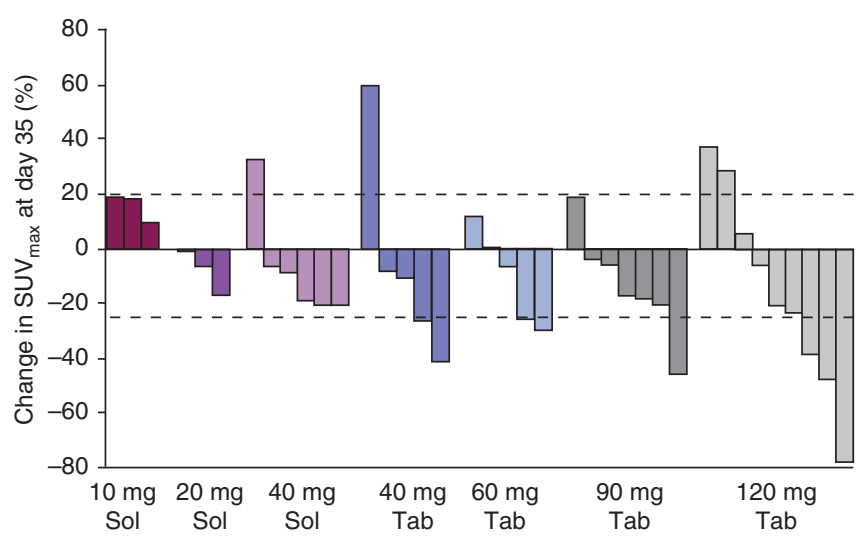

Figure 3 Percentage change in $S U V_{\max }$ assessed by FDG-PET. Abbreviations: FDG-PET = fluorodeoxyglucose positron emission tomography; Sol= solution; SUVmax = standard uptake value; Tab = tablet.

above (40 mg tablet $n=2 / 5,60 \mathrm{mg} n=2 / 5,90 \mathrm{mg} n=1 / 7$ and $120 \mathrm{mg} n=3 / 9 \mathrm{BID}$; Figure 3).

\section{DISCUSSION}

This study presents the first clinical results of the dual mTORC1/ mTORC2 inhibitor, AZD8055. AZD8055 has a manageable tolerability profile, however, a rise in transaminases in the absence of elevated bilirubin levels was observed in most cohorts and was dose limiting; the MTD of AZD8055 being defined as $90 \mathrm{mg}$ BID. Other AEs reported in this study were fatigue, nausea, decreased appetite and diarrhoea. The AEs that were assessed to be related to AZD8055 include as follows: increased ALT, increased AST and fatigue. Rapalogues have been reported to induce frequent skin rash and mucositis (O'Donnell et al, 2008). In our trial, fewer skin toxicities were observed with AZD8055 than those seen in previous clinical studies of rapalogues (O'Donnell et al, 2008). Dose-related, but reversible elevation of transaminases was observed. The rises in transaminases were managed with dose interruptions or reductions yielding full recovery within 71 days for the majority of cases. Interestingly, altered liver function is not a toxicity that has been described with mTOR inhibitors such as temsorilmus (Raymond et al, 2004) and everolimus (O'Donnell et al, 2008). Also, it has not been a commonly observed toxicity with PI3K pathway inhibitors (Kong and Yamori, 2009; Pal et al, 2010). Thus, hepatic dysfunction under AZD8055 could either be considered as an 'on-target' effect of inhibiting mTORC2 or as an 'off-target' 
chemical effect of AZD8055 on normal hepatocytes. Ongoing phase I trials of other dual mTORC1/mTORC2 inhibitors such as AZD2014, INK-128 and OSI-027 may provide information on specific liver enzyme deregulation related to mTORC2 inhibition.

PK data after administration of a 40 -mg dose of either solution or tablet formulation were similar, except for a short delay in timeto-peak as would be anticipated by the change to a solid dosage form, albeit a rapidly dissolving tablet. The proportion of AZD8055 excreted unchanged in the urine was minimal after single dosing at all dose levels, indicating that the renal route does not have a significant role in the elimination of AZD8055. However, as a human radio-labelled mass balance study has not been conducted, it is unknown what proportion of AZD8055 dose would be recovered in the faeces or other compartments following metabolic breakdown, or what proportion of the metabolites would be eliminated in the urine.

mTORC1 inhibitors have previously been shown to indirectly increase AKT phosphorylation (O'Reilly et al, 2006). Therefore, a reduction in AKT phosphorylation is believed to be a measure of mTORC2 inhibition. Pharmacodynamic analysis of PBMC data at $2 \mathrm{~h}$ post dose in the MTD cohort showed a transient reduction in the phosphorylation of AKT in all patients with baseline $>5 \%$ (6/10 patients). However, the assay in PBMCs was often made impossible by very low levels of AKT phosphorylation at baseline; therefore no conclusions can be drawn on mTORC2 inhibition in PBMCs in this study. In addition, the transient reduction in AKT phosphorylation may be consistent with the short half-life of AZD8055. A sensitive assay based on platelet-rich plasmas has now been instituted for future trials. 4E-BP1 phosphorylation at the threonine $e^{37 / 46}$ site has been shown to be a PD marker of mTORC1 activity in preclinical models (Chresta et al, 2010), but it is not reproducibly measured at the threonine ${ }^{70}$ site in healthy human PBMCs (Boulay et al, 2004). It was not possible to demonstrate target inhibition in tumour tissue; however, as only two pre- and post-treatment biopsies were analysed in this study, it is not possible to draw any conclusions.

Seven patients had stable disease for $\geqslant 4$ months in a range of primary tumour locations. Fluorodeoxyglucose positron emission tomography showed metabolic responses at $40 \mathrm{mg}$ BID and above indicating changes in glucose homeostasis induced by AZD8055. However, the use of FDG-PET as a PD biomarker, as opposed to a response indicator, requires further validation and does not predict response as in the case of KIT inhibitors used to treat gastrointestinal stromal disorders (Fuster et al, 2011).

Despite the presence of sustained tumour stabilisation and delayed disease progression, there may be limited tumour shrinkage with targeted agents that are cytostatic in action,

\section{REFERENCES}

Albert S, Serova M, Dreyer C, Sablin MP, Faivre S, Raymond E (2010) New inhibitors of the mammalian target of rapamycin signaling pathway for cancer. Expert Opin Investig Drugs 19: 919-930

Boulay A, Zumstein-Mecker S, Stephan C, Beuvink I, Zilbermann F, Haller R, Tobler S, Heusser C, O'Reilly T, Stolz B, Marti A, Thomas G, Lane HA (2004) Antitumor efficacy of intermittent treatment schedules with the rapamycin derivative RAD001 correlates with prolonged inactivation of ribosomal protein S6 kinase 1 in peripheral blood mononuclear cells. Cancer Res 64: 252-261

Carew JS, Kelly KR, Nawrocki ST (2011) Mechanisms of mTOR inhibitor resistance in cancer therapy. Target Oncol 6: 17-27

Chresta CM, Davies BR, Hickson I, Harding T, Cosulich S, Critchlow SE, Vincent JP, Ellston R, Jones D, Sini P, James D, Howard Z, Dudley P, Hughes G, Smith L, Maguire S, Hummersone M, Malagu K, Menear K, Jenkins R, Jacobsen M, Smith GC, Guichard S, Pass M (2010) AZD8055 is a potent, selective, and orally bioavailable ATP-competitive mammalian target of rapamycin kinase inhibitor with in vitro and in vivo antitumor activity. Cancer Res 70: 288-298 particularly anti-angiogenic therapy (de Langen et al, 2011; Oberstein and Saif, 2012). Therefore, RECIST may not be the most appropriate method to evaluate response with molecularly targeted agents, and molecular imaging techniques may be better suited for this purpose (de Langen et al, 2011). Reasons for lack of a significant objective response in this trial could include heterogenous tumour types, lack of selection based on mutation status (e.g., PI3K or PTEN mutation) or inability to achieve sustained target inhibition with the current schedule. An alternative dosing schedule of 3 weeks on drug and 1 week off may have provided similar exposure but avoided the increased transaminases typically seen between weeks 3 and 5 .

In conclusion, AZD8055 as a first-in-class agent has revealed a toxicity profile which is different from rapalogue mTOR inhibitors, which includes the presence of elevated transaminase levels. It may be possible to mitigate the rise in transaminases seen in this study through modification of the dosing schedule; however, AZD8055 is not being developed further. A follow-up compound, AZD2014, is currently being investigated in phase I and no rise in transaminases has been reported. Thus, dual inhibition of mTORC1/2 remains a promising therapeutic target and other mTOR kinase inhibitors in development are showing promising results.

\section{ACKNOWLEDGEMENTS}

Medical writing services were provided by Emma Burke of iMed Comms and were funded by AstraZeneca. The study was sponsored by AstraZeneca and supported by funding from Cancer Research UK (grant number: C309/A8274/A309/A11566; C51/ A6883); the Experimental Cancer Medicine Network (grant number: C51/A7401/C12540/A15573); and by a National Institute for Health Research Biomedical Research Centre grant, awarded jointly to The Royal Marsden NHS Foundation Trust and The Institute of Cancer Research.

\section{Conflict of interest}

Elisabeth Oelmann, Lynda Grinsted and Wendy Burke are all employees of AstraZeneca and hold AstraZeneca stocks or shares. Rosemary Taylor is a contractor employed by AstraZeneca. Dr Banerji has previously been a member of an AstraZeneca advisory board. Dr Kurzrock has received research funding from AstraZeneca. All remaining authors declare no conflict of interest.

Supplementary Information accompanies the paper on British Journal of Cancer website (http://www.nature.com/bjc) Hsueh T, Chen Y, Wang W, Youngkin D, Liau L, Martin N, Becker D, Bergsneider M, Lai A, Green R, Oglesby T, Koleto M, Trent J, Horvath S, Mischel PS, Mellinghoff IK, Sawyers CL (2008) Antitumor activity of rapamycin in a Phase I trial for patients with recurrent PTENdeficient glioblastoma. PLoS Med 5: e8

de Langen AJ, van den Boogaart V, Lubberink M, Backes WH, Marcus JT, van TH, Pruim J, Brans B, Leffers P, Dingemans AM, Smit EF, Groen HJ, Hoekstra OS (2011) Monitoring response to antiangiogenic therapy in non-small cell lung cancer using imaging markers derived from PET and dynamic contrast-enhanced MRI. J Nucl Med 52: $48-55$

Europeans Medicines Agency (2011) Temsirolimus Summary of Product Characteristics. http://www.ema.europa.eu/docs/en_GB/document_library/ EPAR_-_Product_Information/human/000799/WC500039912.pdf 19 September 2011, accessed 23 February 2012

Europeans Medicines Agency (2012) Everolimus Summary of Product Characteristics. http://www.ema.europa.eu/docs/en_GB/document_library/ 
EPAR_-_Product_Information/human/001038/WC500022814.pdf 1 January 2012, accessed 23 February 2012

Faivre S, Kroemer G, Raymond E (2006) Current development of mTOR inhibitors as anticancer agents. Nat Rev Drug Discov 5: 671-688

Feldman ME, Apsel B, Uotila A, Loewith R, Knight ZA, Ruggero D, Shokat KM (2009) Active-site inhibitors of mTOR target rapamycin-resistant outputs of mTORC1 and mTORC2. PLoS Biol 7: e38

Fuster D, Ayuso JR, Poveda A, Cubedo R, Casado A, Martinez-Trufero J, Lopez-Pousa A, Del Muro XG, Lomena F, Maurel J, Pons F (2011) Value of FDG-PET for monitoring treatment response in patients with advanced GIST refractory to high-dose imatinib. A multicenter GEIS study. Q J Nucl Med Mol Imaging 55: 680-687

Guertin DA, Sabatini DM (2007) Defining the role of mTOR in cancer. Cancer Cell 12: 9-22

Gupta M, Ansell SM, Novak AJ, Kumar S, Kaufmann SH, Witzig TE (2009) Inhibition of histone deacetylase overcomes rapamycin-mediated resistance in diffuse large B-cell lymphoma by inhibiting Akt signaling through mTORC2. Blood 114: 2926-2935

Kong D, Yamori T (2009) Advances in development of phosphatidylinositol 3-kinase inhibitors. Curr Med Chem 16: 2839-2854

Liu P, Cheng H, Roberts TM, Zhao JJ (2009) Targeting the phosphoinositide 3-kinase pathway in cancer. Nat Rev Drug Discov 8: 627-644

O'Donnell A, Faivre S, Burris III HA, Rea D, Papadimitrakopoulou V, Shand N, Lane HA, Hazell K, Zoellner U, Kovarik JM, Brock C, Jones S, Raymond E, Judson I (2008) Phase I pharmacokinetic and pharmacodynamic study of the oral mammalian target of rapamycin inhibitor everolimus in patients with advanced solid tumors. J Clin Oncol 26: $1588-1595$
O’Reilly KE, Rojo F, She QB, Solit D, Mills GB, Smith D, Lane H, Hofmann F, Hicklin DJ, Ludwig DL, Baselga J, Rosen N (2006) mTOR inhibition induces upstream receptor tyrosine kinase signaling and activates Akt. Cancer Res 66: 1500-1508

Oberstein PE, Saif MW (2012) Safety and efficacy of everolimus in adult patients with neuroendocrine tumors. Clin Med Insights Oncol 6: 41-51

Pal SK, Reckamp K, Yu H, Figlin RA (2010) Akt inhibitors in clinical development for the treatment of cancer. Expert Opin Investig Drugs 19: 1355-1366

Raymond E, Alexandre J, Faivre S, Vera K, Materman E, Boni J, Leister C, Korth-Bradley J, Hanauske A, Armand JP (2004) Safety and pharmacokinetics of escalated doses of weekly intravenous infusion of CCI-779, a novel mTOR inhibitor, in patients with cancer. J Clin Oncol 22: 2336-2347

Sarbassov DD, Ali SM, Sengupta S, Sheen JH, Hsu PP, Bagley AF, Markhard AL, Sabatini DM (2006) Prolonged rapamycin treatment inhibits mTORC2 assembly and Akt/PKB. Mol Cell 22: 159-168

Thoreen CC, Kang SA, Chang JW, Liu Q, Zhang J, Gao Y, Reichling LJ, Sim T, Sabatini DM, Gray NS (2009) An ATP-competitive mammalian target of rapamycin inhibitor reveals rapamycin-resistant functions of mTORC1. J Biol Chem 284: 8023-8032

Vivanco I, Sawyers CL (2002) The phosphatidylinositol 3-Kinase AKT pathway in human cancer. Nat Rev Cancer 2: 489-501

Young H, Baum R, Cremerius U, Herholz K, Hoekstra O, Lammertsma AA, Pruim J, Price P (1999) Measurement of clinical and subclinical tumour response using [18F]-fluorodeoxyglucose and positron emission tomography: review and 1999 EORTC recommendations. European Organization for Research and Treatment of Cancer (EORTC) PET Study Group. Eur J Cancer 35: 1773-1782

This work is published under the standard license to publish agreement. After 12 months the work will become freely available and the license terms will switch to a Creative Commons Attribution-NonCommercial-Share Alike 3.0 Unported License. 